\title{
Около тюрьмы
}

ОМЕЛЬЧЕНКО Е. Л., ПЭЛЛОТ ДЖ. (РЕД.). (2015). ОКОЛО ТЮРЬМЫ: ЖЕНСКИЕ СЕТИ ПОДДЕРЖКИ ЗАКЛЮЧЕННЫХ. СПБ.: АЛЕТЕЙЯ. 240 С. (КАЧЕСТВЕННЫЕ МЕТОДЫ В СОЦИАЛЬНЫХ ИССЛЕДОВАНИЯХ). ISBN 978-5-906792-16-7

\section{Ксения Аверкиева}

Кандидат географических наук, научный сотрудник Института географии РАН Адрес: Старомонетный пер., д. 29, Москва, Российская Федерация, 119017

E-mail: xsenics@yandex.ru

Недавно мы с коллегами столкнулись с неожиданными статистическими данными: в одном поселке, где расположены две исправительные колонии, за прошлый год среди «вольного» населения было зарегистрировано два брака, а среди заключенных - 120. Даже если учесть, что за решеткой находятся около 2500 человек, а в поселке проживают около 1000 жителей, такой «диспаритет» все равно показался необычным. Собирая данные для исследований по «тюремной экономике» ${ }^{1}$ и анализируя материалы сайтов региональных управлений ФСИН, мы нередко встречали новости о большом количестве свадеб, сыгранных в колониях в последнее время. Почему заключенные стали так часто заключать браки? Что это такое семья с тем, кто находится по другую сторону решетки и не выйдет еще много лет? Кто решается связать свою жизнь с совсем незнакомым «околотюремным» миром? Казалось бы, ответить на такой вопрос можно, только получив личный опыт взаимодействия с исправительной системой. Но книга «Около тюрьмы: женские сети поддержки заключенных», вышедшая в 2015 году в Санкт-Петербурге под редакцией Елены Омельченко и Джудит Пэллот, позволяет взглянуть на эту тему со стороны.

В коллективе авторов книги - российские социологи и их зарубежные коллеги из Оксфорда: профессор социальной географии и доктор философии. В книге представлены результаты двух исследовательских проектов ${ }^{2}$, поэтому она будет интересна не только специалистам-социологам, но и всем, кто интересуется тюремной и околотюремной тематикой, а также «невидимыми и неслышимыми со-

(С) Аверкиева К. В., 2015

() Центр фундаментальной социологии, 2015

1. Первые результаты исследований были опубликованы в статьях: Аверкиева К. В. (2014). Территориальная организация исправительных учреждений России // Известия РАН. Серия географическая. № 3. С. 19-34; Аверкиева К. В. (2014). Географическое положение как фактор разнообразия «тюремной» экономики // Разнообразие как фактор и условия территориального развития / Под ред. В. Н. Стрелецкого. Часть І. Главы 1-3. М.: Эслан. С. 254-269.

2. Исследовательские проекты «Около тюрьмы: идентичность и повседневность родственниц заключенных» (грант НИУ ВШЭ № 12010152), «Наказание и социологическое конструирование гендера в постсоветской России: влияние тюремной системы на родственников заключенных» (AHRC AH/ Hoo $8349 / 1$, Oxford). 
обществами». В своих работах ученые опирались на глубинные биографические интервью, российские и зарубежные публикации, посвященные тематике тюремного заключения и отношениям между заключенными и их родственниками. Анализируя российскую специфику, исследователи обращаются к различным теоретическим концепциям, в том числе к теории двойной структурации Гидденса.

Книга состоит из двух частей. В первой части помещены статьи, посвященные анализу различных сторон женской опеки заключенных. Вторая предлагает читателям библиографические нарративы - интервью с подругами, женами и матерями мужчин-заключенных, прошедшие литературную редакцию Надежды Нартовой. Затрагивая такую тонкую и болезненную для общества тему, авторы сумели уйти от оценок. Образы заключенных не романтизируются, но и не имеют яркой негативной окраски. Спутницы отбывающих наказания - не обязательно «декабристки» или «подруги гангстеров», это разные женщины, оказавшиеся в новой для себя и непростой жизненной ситуации.

Как и другие исследователи тюремных и «околотюремных» вопросов, авторы сталкивались с дефицитом или даже отсутствием научных публикаций, посвященных российской тюрьме. Пенитенциарная система остается крайне закрытой в буквальном смысле, поэтому исследование базировалось на интервью с теми, кто остается по эту сторону решетки, а также на материалах, размещенных в Сети интернет. Как показывает мой небольшой опыт исследования сходной проблематики, даже те, кто в прошлом имел отношение к исправительным учреждениям, и особенно сотрудники ФСИН после ухода с работы, не особенно словоохотливы. Они, обладая значительными ресурсами внутри системы, очень насторожены по отношению к любому интересу к самой системе и непосредственно к ним. Исследователям остается судить о роли женщин в ресоциализации заключенных лишь со слов их родственниц и подруг, а фокус исследования смещается к жизненным стратегиям женщин и феномену «квазизаключенности».

Книга позволяет понять, что лишение свободы сказывается не только на самих заключенных, и наказаны бывают не только сами преступившие закон, но и их родственники. Клеймо жены/подруги или даже матери заключенного нередко ломает привычный уклад жизни многих женщин. Опираясь на материалы зарубежных исследователей «тюремной» социологии, авторы показывают, как изменилось восприятие спутниц и родственниц заключенных в науке и обществе, демонстрируют силу общественного давления на современных «декабристок» и одновременно прослеживают, как заключение любимого человека способствует мобилизации всех внутренних сил женщины. Жизненные истории иллюстрируют, как женщины повышают свою юридическую грамотность, чтобы помочь своим мужьям, как они ищут новую работу, чтобы иметь возможность посылать передачи и приезжать на свидания к любимым. Даже те, кто познакомился с заключенным по переписке и имеет негласный статус «заочниц», - меняются. Сам факт того, что женщины обрели родственную душу или хотя бы друга, поднимает их самооценку, придает уверенности. 
Обратная сторона медали - это жесткие правила и унижения, с которыми женщины сталкиваются, оказавшись около системы ФСИН, приезжая на свидания к «своим» мужчинам. Одна поездка обходится в 10-20 тыс. рублей, в зависимости от того, как далеко от дома расположено исправительное учреждение. Иногда им приходится преодолевать не одну тысячу километров, чтобы попасть к мужьям или сыновьям. Нередко помимо поезда требуется поездка на такси, иногда и размещение в поселке, потому что посещение колонии разрешено только в определенные часы. На каждое свидание можно привезти до 20 кг передачи разрешенных продуктов, одежды и предметов первой необходимости. Перед свиданием всех ждет унизительная процедура досмотра (хотя за небольшую взятку «свиданщицы» ${ }^{3}$ разрешают проносить в комнаты для свиданий даже алкоголь), а также постоянное презрение со стороны персонала колонии. Вроде бы сын за отца не отвечает, а жена за мужа?

Читая истории о трудностях пути в исправительные учреждения, в очередной раз задумываешься о логике территориального размещения колоний и тюрем. Казалось бы, времена, когда наказывали расстоянием, уже прошли. Труднодоступные колонии, которые строились в ресурсных регионах, уже утратили свое экономическое значение, их обслуживание оборачивается все большими издержками. Но система очень инерционна и пока еще не очень адекватна системе расселения России. Стоит ли приблизить исправительные учреждения к основной полосе расселения - дискуссионный вопрос, который может стать предметом отдельного исследования. Пока же расстоянием наказывают не только заключенных, но и их родственников, преодолевающих сотни и даже тысячи километров, чтобы их поддержать.

Авторы книги уделяют много внимания самим женщинам, решившим дожидаться своих избранников долгие годы тюремного заключения. Отдельно рассматривается специфика самоидентификации женщин и феномен «декабристок», прослеживается история и этого явления и смена общественной оценки такого нравственного подвига. И авторы, и респонденты отмечают, что образ романтичных натур, устремившихся в Сибирь за своими мятежными мужьями, сильно изменился за последние годы. Какая романтика, если приходится ездить с баулами еды по всей стране и обивать пороги всевозможных инстанций, чтобы узнать о своих родственниках хоть что-то? Работая с материалами интервью, авторы выделили несколько стратегий ожидания заключенных, из которых лишь одну, мобилизационную, можно соотнести с «декабризмом». В остальных случаях давление социума и осложнение материального положения превращают «декабристку» в «солдатку», которой трудно приспособиться к новым условиям, которая снижает свой социальный статус и обречена на все большую изоляцию.

Хотя книга в большей степени посвящена женщинам, она содержит много информации и о самих сидельцах. Каждая биографическая история спутницы

3. Специальные сотрудницы, которые досматривают приехавших на свидания и содержимое передач. 
заключенного помогает понять, что происходит с мужчинами в тюрьме. Все респондентки говорят об опасности такого рода социального исключения: мужчины теряют здоровье (из-за условий содержания, образа жизни, неправильного питания), утрачивают коммуникативные и трудовые навыки (в зонах почти нет производства, обучение тоже не всегда адекватно экономическим реалиям), становятся, с одной стороны, озлобленными, с другой - беспомощными из-за постоянного давления репрессивной системы. Казалось бы, эпитет «беспомощный» не очень подходит к преступникам, отбывающим наказание, однако сравнение заключенных, особенно к концу срока заключения, с детьми и даже со слепыми котятами встречается не только в сентиментальных рассказах их жен и подруг. Такие оценки приводят и социологи, и другие исследователи пенитенциарной системы. Именно поэтому многие женщины не бросают своих мужей и осознают особую ответственность, воспринимают свое ожидание как долг - «неужели государству нужны больные и озлобленные люди, выходящие из тюрьмы?». И остается только поражаться, какими средствами, правдами и неправдами им приходится заботиться о своих родственниках и избранниках.

После прочтения книги приходится задуматься о множестве противоречий, которые существуют в системе поддержки заключенных. Исходя из опыта большинства респонденток, можно понять, что использование мобильного телефона в исправительных учреждениях (притом что пользование мобильным телефоном в учреждениях законодательно запрещено) - обязательный залог связи, которая позволяет заключенным не выпадать из реальности и чувствовать поддержку близких, ежедневно общаться с детьми и женами. Казалось бы, вот он - инструмент ресоциализации, и стоит задуматься о разрешении мобильных телефонов, тем более что «на зону» они все равно попадают любыми возможными путями. С другой стороны, стоит только представить, сколько новых преступлений совершается ежедневно благодаря тому, что теперь «руководить делами» криминальные авторитеты могут из-за решетки, и вопрос разрешения мобильной связи отпадает сам собой.

Как понять, что важнее: оградить общество от всех возможных контактов с заключенными, твердо контролируя использование мобильных телефонов в колониях, или возвращать в общество тех, кто еще готов исправиться и благодаря ежедневному общению с семьей может вернуться и полноценно включиться в жизнь? В некоторых странах такой дилеммы нет: заключенные могут пользоваться мобильными телефонами, но в них запрограммированы только несколько номеров близких родственников. Принимать звонки с других номеров и звонить на другие номера оттуда просто невозможно. Но внедрение аналогичной практики в российскую систему исполнения наказаний перекроет многие каналы нелегального снабжения заключенных (ведь чаще всего мобильники попадают к заключенным через охранников), а представителям системы это невыгодно.

Другой вопрос, который встает перед читателем, - это оценка роли «заочниц» в системе поддержки заключенных. Заочницами называют тех женщин, которые 
познакомились со своими мужьями или партнерами уже после того, как те попали в заключение. Официально разрешенная практика почтовой переписки или нелегальные варианты знакомств по телефону или через интернет легко позволяют заключенным находить себе подруг. Именно поэтому сейчас так часты браки между заключенными и женщинами «с воли» - без штампа в паспорте очень трудно попасть на длительное свидание. Интервью, приведенные в книге, показывают преимущественно положительные стороны такого общения: женщины спасаются от одиночества, находят спутников, обретают новый опыт, мужчины в тюрьмах получают стимул к освобождению и тоже «мобилизуются», потому что долгосрочные свидания разрешены лишь тем, кто не нарушает режим. Но известны и многочисленные случаи обмана, когда мужчины находят себе подруг лишь для того, чтобы они присылали хорошие передачи и приезжали скрасить их досуг. Сколько таких обманутых женщин? Как общение с заочницами влияет на самих заключенных, на их повседневность и судьбу после освобождения?

В книге не хватает взгляда «с другой стороны», тех, кто непосредственно работает с заключенными и может дать свою оценку роли женщин в поддержке, перевоспитании, социализации или ресоциализации мужчин в заключении. Безусловно, персонал колоний имеет возможность наблюдать за заключенными и видеть, как на них влияет общение с родственниками и подругами. Наверняка есть какаято, хотя бы неформальная, статистика и экспертные оценки разных инструментов поддержки заключенных. Но система закрыта, и остается надеяться лишь на готовность самих заключенных, отбывших сроки и вышедших на свободу, включиться в исследования и помочь ученым тоньше понять то, что происходит по ту сторону решетки. Одна из попыток работы с бывшими осужденными уже реализована в исследовании тех же авторов - это книга «До и после тюрьмы: женские истории» ${ }^{4}$. В ней, основываясь на материалах интервью женщин, прошедших через исправительные учреждения, авторы рассматривают гендерные аспекты заключения, много внимания уделяя устройству быта колоний и его влиянию на поведение и ресоциализацию женщин, преступивших закон.

Зная многие трудности, с которыми приходится сталкиваться тем, кто изучает российскую пенитенциарную систему, невольно восхищаешься авторами, которые так долго и внимательно изучают женскую сторону заключения. Почему-то в России социологии женщин в тюрьме уделяется гораздо больше внимания, нежели социологии мужчин, находящихся в заключении. Возможно, на это повлияли яркие узницы нового времени (девушки из группы Pussy Riot) и активисты общественных организаций, в частности Ольга Романова. Возможно, сохраняется мода на изучение гендерных проблем, поэтому исследования женских практик тюремного заключения или поддержки заключенных имеют больше шансов получить финансирование. Хочется надеяться на то, что авторы сохранят интерес к теме и будут публиковать новые статьи. Возможно, вопросы, затронутые в данной книге,

4. Омельченко Е. Л. (Ред.). (2012). До и после тюрьмы: женские истории. СПб.: Алетейя. 
помогут новым исследователям обратиться к социологии исправительных учреждений и появятся новые работы.

\section{Close to Prison}

\section{Ksenia Averkieva}

Researcher, Institute of Geography of the Russian Academy of Sciences

Address: Staromonetniy Pereulok, 29, Moscow, Russian Federation 119017

E-mail:xsenics@yandex.ru

Review: Review: Okolo tjur'my: zhenskie seti podderzhki zakljuchennyh [Close to Prison: Women's Networks of Prisoners Support] edited by Elena Omelchenko and Judith Pallot (Saint-Petersburg: Aleteija, 2015) (in Russian). 